\title{
Correlation between TSC1 gene polymorphism and epilepsy
}

\author{
XIULI JIANG ${ }^{1}$, JIAJIA CHEN ${ }^{2}$, QUANJIANG SONG ${ }^{3}$, WEILING WANG ${ }^{4}$, \\ GUANGYAN ZHANG ${ }^{5}$ and $\mathrm{YE} \mathrm{LI}^{1}$
}

\begin{abstract}
Departments of ${ }^{1}$ Neurology and ${ }^{2}$ Clinical Laboratory, People's Hospital of Rizhao; ${ }^{3}$ Department of Internal Medicine, Women and Chindren's Health Care Hospital of Rizhao, Rizhao, Shandong 276800; Departments of ${ }^{4}$ Ultrasonography and ${ }^{5}$ Clinical Laboratory, People's Hospital of Zhangqiu, Jinan, Shandong 250000, P.R. China
\end{abstract}

Received August 7, 2017; Accepted October 5, 2017

DOI: $10.3892 / \mathrm{etm} .2017 .5345$

\begin{abstract}
The correlation between tuberous sclerosis complex 1 (TSC1) gene polymorphism and epilepsy was studied. In total, 38 patients with epilepsy treated in People's Hospital of Rizhao from May 2015 to June 2016 were selected as study subjects, as the observation group, 38 healthy people in the same period were selected as the control group. Polymerase chain reaction-restriction fragment length polymorphism (PCR-RFLP) was used to study the polymorphism of TSC1 gene in the above study subjects. The mRNA expression of $\mathrm{TSC} 1$ gene in the observation group and the control group was measured by fluorescence quantitative PCR, the expression of TSC1 protein in the control and observation group was measured by western blotting and ELISA. The polymorphisms of TSC1 gene in control group and observation group were analyzed by PCR-RFLP. There were three genotypes of TCS1 gene locus 142 in healthy population: CC (79.3\%), CA (13.9\%) and AA (6.8\%), there were also three genotypes at locus 142 in the observation group: CC (21.3\%), CA (26.4\%) and AA (52.3\%), there was significant difference in the genotypes at locus 142 between healthy population and the patients with epilepsy $(\mathrm{P}<0.05)$. It was observed by fluorescence quantitative PCR that there was no significant difference in the mRNA expression of TSC1 gene between the control group and the observation group $(\mathrm{P}>0.05)$. The expression of $\mathrm{TSC} 1$ gene was detected by western blot method. Western blotting showed no significant difference in TSC1 protein expression between the two groups $(\mathrm{P}>0.05)$. However, by determining the activity of TSC1 protein in the observation group and the control group by ELISA, it was found that TSC1 activity in healthy human body $(8.95 \pm 2.41 \mathrm{U} / \mathrm{ml})$ was much lower than that in the patients with epilepsy $(29.27 \pm 4.06 \mathrm{U} / \mathrm{ml})$, the difference was statistically significant $(\mathrm{P}<0.05)$. It was found that locus 142 may be located at the active center of TSC1 enzyme by homology
\end{abstract}

Correspondence to: Dr Ye Li, Department of Neurology, People's Hospital of Rizhao, 126 Tai'an Road, Rizhao, Shandong 276800, P.R. China

E-mail: yju8w2@163.com

Key words: tuberous sclerosis complex 1, gene polymorphism, epilepsy, SWISS-MODEL, homology modeling modeling of SWISS-MODEL, the mutation of locus 142 could lead to the change of TSC1 activity. The polymorphism of locus 142 in TSC1 gene is correlated with epilepsy, that is, the increase of CA and AA content in locus 142 leads to the occurrence of epilepsy.

\section{Introduction}

Epilepsy is one of the common severe chronic psychiatric disorders, currently, there are $~ 54$ million people suffering from epilepsy disease globally (1). Now the treatment of epilepsy is mainly through the use of antiepileptic drugs such as phenytoin, ethoxylamine, but clinical statistics show that (2), there is no specific treatment for epilepsy drugs, and because of long-term use of antiepileptic drugs, $\sim 40 \%$ of patients with epilepsy are resistant to epilepsy drugs (3). Epilepsy pathogenesis and the cause of antiepileptic is not clear, which directly lead to the increase of epilepsy mortality year by year. As a neuropathic syndrome (4), tuberous sclerosis complex (TSC) is considered to be a genetic disease caused by chromosomal abnormalities, the main mechanism is the abnormalities of TSC1 and TSC2 protein (5). Studies have found that TSC1 protein is mainly involved in cell proliferation, division and cell adhesion, and in recent years with the in-depth research on TSC1 gene (6), it was observed that TSC1 protein can interact with TSC2 protein, when TSC1 coding abnormality occurs, it will lead to inhibition of cell proliferation processing, causing accelerated cell proliferation (7). In addition, by detecting TSC1 gene in patients with epilepsy, skin pigmentation, and vascular fibroma, it was found that the above patients had different degree of TSC1 gene mutation (e.g., locus 129 and locus 174), leading to abnormal protein function (8). We investigated the epilepsy patients in Rizhao hospital, explored the genetic polymorphisms of TSC1 in epilepsy and healthy people, in order to improve the diagnostic accuracy of epilepsy disease from the genetic level, and to provide a certain theoretical and experimental basis for early diagnosis and early treatment of epilepsy.

\section{Materials and methods}

The study subjects were the 38 epilepsy patients treated in People's Hospital of Rizhao from May 2015 to June 2016, marked as observation group, including 20 males and 18 females, the average age $52.3 \pm 8.9$ years; 38 healthy people 
Table I. TSC1 primer sequence.

\begin{tabular}{lcc}
$\begin{array}{l}\text { Name of } \\
\text { primer }\end{array}$ & Length & Sequence \\
\hline TSC1-F & $21 \mathrm{bp}$ & ATGAGTCGTAGCTAGTCGAAG \\
TSC1-R & $24 \mathrm{bp}$ & TACGTCGGAGCTGATCGATGCTAC \\
\hline
\end{tabular}

TSC1, tuberous sclerosis complex 1 .

at the same period were selected as the control group, including 20 males and 18 females, with an average age of $51.2 \pm 9.5$ years The study was approved by the Ethics Committee of People's Hospital of Rizhao and informed consents were signed by the patients and/or guardians.

Inclusion criteria, in the study, the epilepsy patients selected were based on the criteria of diagnosis of epilepsy disease in epilepsy and epilepsy syndrome (9).

Exclusion criteria: i) patients with other neurological disorders; ii) patients younger than 10 years of age.

Main reagents: Molecular reagents, Pfu high-fidelity DNA polymerase (Thermo Fisher Scientific, Shanghai, China); dNTP, 6X buffer, RNA extraction kit, reverse transcription kit, PCR product purification kit and fluorescence quantitative PCR kit (Takara, Dalian, China); genomic and protein extraction kits (Axygen, Union City, CA, USA); EcoR72I restriction endonucleases, TSC1 and glyceraldehyde 3-phosphate dehydrogenase (GAPDH) antibodies (NEB Corp., Beijing, China); agarose, GodView (Solarbio Science and Technology Co., Ltd., Suzhou, China); the rest of the chemical reagents were purchased from Sangon Biotechnology Co., Ltd. (Shanghai, China).

Main instruments: Fluorescence quantitative PCR (ABI, Foster City, CA, USA), protein electrophoresis (Beijing Liuyi Biotechnology Co., Ltd., Beijing, China), multifunctional microplate reader (Bio-Rad, Hercules, CA, USA).

\section{Methods}

Genome extraction. Five milliliters of the elbow vein blood was taken from the observation group and the control group, centrifuged at $1,000 \mathrm{x} \mathrm{g}$ for $5 \mathrm{~min}$, the blood cells were collected. The genome of healthy people and epilepsy patients was extracted according to the instructions of the Axygen genome extraction kit (10).

Polymerase chain reaction-restriction fragment length polymorphism (RFLP). The TSC1 gene sequence was searched from NCBI website, and primers were designed based on the sequence. The TSC1 gene sequence of healthy people and epilepsy patients was amplified. The primer sequences are shown in Table I.

The obtained PCR product was purified by PCR product purification kit, then ligated with pMD19T simple vector, and the recombinant vector was introduced into Escherichia coli, and then the positive clones were screened in the resistant plate (LB + AMP) and sequenced.

TSC1 gene polymorphism digestion test. TSC1 polymorphism test, the TSC1 gene was amplified by PCR method using the extracted genome of healthy people and epilepsy patients as template, and then the PCR product was digested
Table II. Fluorescence PCR primers.

\begin{tabular}{ll}
\hline Name of primer & \multicolumn{1}{c}{ Sequence } \\
\hline qTSC1-F & TGCTAGCTGAGTCGATCGTACG \\
qTSC1-R & CGTAGCTGATGCTAGTCGAC \\
GAPDH-F & CGTAGGGATCGTAGCTAGC \\
GAPDH-R & CGTAGTCGATGCTAGCTGCG
\end{tabular}

PCR, polymerase chain reaction; TSC1, tuberous sclerosis complex 1; GAPDH, glyceraldehyde 3-phosphate dehydrogenase.

by EcorR72I restriction enzyme according to the restriction site predicted by primer (ABI) (11).

Fluorescence quantitative PCR. RNA extraction. In this study, the blood of the observation group and the control group was taken. RNA was extracted and the extraction quality was determined.

In order to study the difference of TSC1 mRNA expression in different treatment on tissues, fluorescence quantitative PCR was conducted using the cDNA obtained by RNA reverse transcription as template. The primer sequences are shown in Table II.

Enzyme-linked immunoreaction. Five milliliters of the elbow vein blood was taken from the observation group and the control group, centrifuged at $1,000 \mathrm{x} \mathrm{g}$ for $5 \mathrm{~min}$, the blood cells were collected, the intracellular total protein was extracted by Axygen kit. After the total protein was quantified by Coomassie Brilliant Blue, the TSC1 protein in different samples was quantified by enzyme-linked immunosorbent assay (ELISA) kit.

Western blotting. Five milliliters of the elbow vein blood was taken from the observation group and the control group, centrifuged at 1,000 $\mathrm{x}$ g for $5 \mathrm{~min}$, the blood cells were collected, the intracellular total protein was extracted by Axygen kit, then sodium dodecyl sulfate-polyacrylamide gel electrophoresis (SDS-PAGE) was conducted ( $0.2 \mathrm{mg}$ total protein). After the protein was transferred, $5 \%$ skim milk powder was added for closing at room temperature for $2 \mathrm{~h}$, then 1:5,000 diluted TSC1 primary antibody was added (Thermo Fisher Scientific), and incubated at room temperature for $2 \mathrm{~h}$, then washed by TBST (3 times, 5 min each), then HRP-labeled secondary antibody was added, incubated at room temperature for $2 \mathrm{~h}$, and then washed by TBST ( 3 times, each $5 \mathrm{~min}$ ) (internal reference was processed with reference to TSC1 protein detection method), and color development solution was added for observation (12).

Statistical analysis. In this study, we analyzed the data by SPSS 19.0 software (SPSS Inc., Chicago, IL, USA). The data were expressed as (mean $\pm \mathrm{SD}$ ), and the difference between the control group and the observation group was analyzed by t-test. $\mathrm{P}<0.05$ for the difference was considered as statistically significant.

\section{Results}

TSC1 gene amplification and sequencing. The TSC1 gene of the epilepsy patients and the healthy population (Fig. 1) 


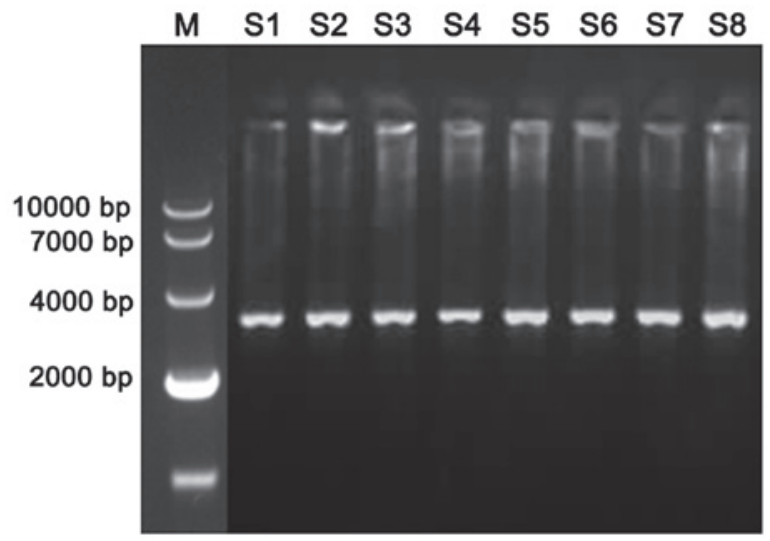

Figure 1. Results of tuberous sclerosis complex 1 (TSC1) gene amplification in healthy people and epilepsy patients. M, DL10,000; S1-S4, TSC1 gene amplification results in epilepsy patients; S5-S8, amplification of TSC1 gene in healthy population.

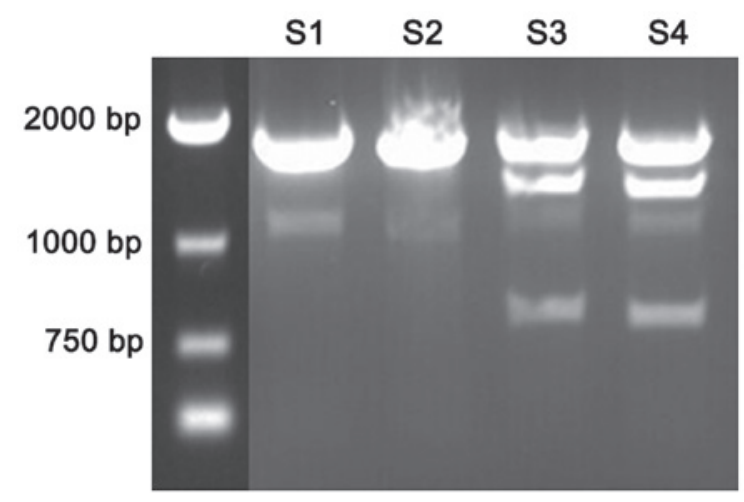

Figure 2. Tuberous sclerosis complex 1 (TSC1) polymorphism in epilepsy patients and healthy people. There were 2 bands in epilepsy patients (S1-S2) TSC1 after digested by EcoR72I; there were 3 bands in healthy population (S3-S4) TSC1 gene after digested by EcoR72I.

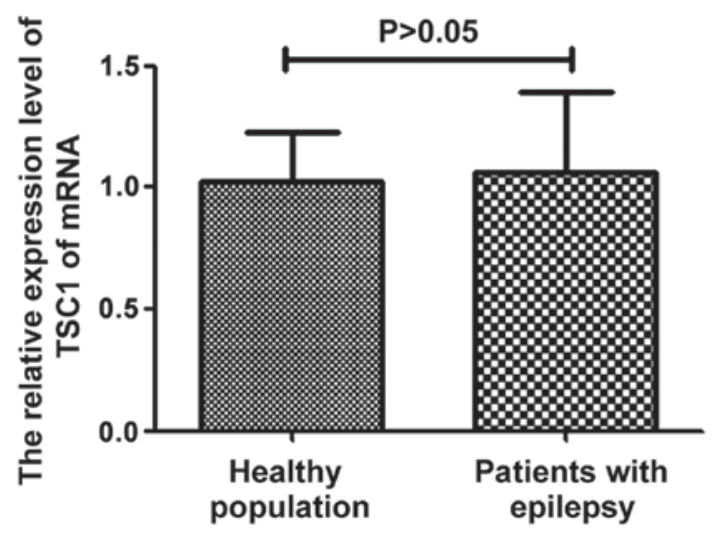

Figure 3. Tuberous sclerosis complex 1 (TSC1) gene mRNA expression differences in epilepsy and healthy people. As can be seen from the figure, the relative expression level of TSC1 in patients with epilepsy was 1.2 times of its mRNA expression in healthy population.

was obtained by using the genome of the control group and the observation group as template. By sequencing TSC1 of epilepsy patients and healthy population (Table III), we found that there were three genotypes at locus 142 in healthy population, CC (79.3\%), CA (13.9\%) and AA (6.8\%), there were also
Table III. Results of TSC1 gene sequencing in epilepsy patients and healthy population.

\begin{tabular}{|c|c|c|c|}
\hline \multirow[b]{2}{*}{ Group } & \multicolumn{3}{|c|}{ Genotype } \\
\hline & $\mathrm{CC}$ & CA & AA \\
\hline Control & $79.3 \%$ & $13.9 \%$ & $6.8 \%$ \\
\hline Observation & $21.3 \%$ & $26.4 \%$ & $52.3 \%$ \\
\hline t-value & 4.31 & 2.14 & 4.86 \\
\hline P-value & $<0.05$ & $>0.05$ & $<0.05$ \\
\hline
\end{tabular}

TSC1, tuberous sclerosis complex 1 .

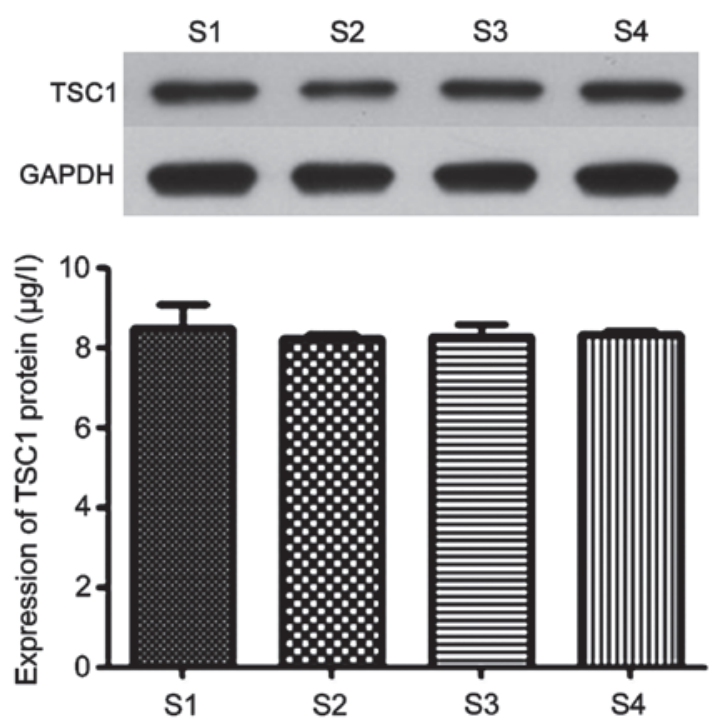

Figure 4. Western blot method to determine expression differences of tuberous sclerosis complex 1 (TSC1) protein in patients with epilepsy and healthy people. S1-S2, expression of TSC1 protein in patients with epilepsy; $\mathrm{S} 3-4$, expression of TSC1 protein in healthy population. It can be seen from the figure, there was no significant difference in terms of TSC1 expression in patients with epilepsy and healthy population.

three genotypes at locus 142 in epilepsy patients, CC (21.3\%), CA (26.4\%) and AA (52.3\%). There was significant difference between the epilepsy patients and healthy population in terms of the genotype $\mathrm{CC}$ and $\mathrm{AA}(\mathrm{P}<0.05)$.

TSC1 polymorphism digestion. By analyzing the sequence of TSC1 gene, it was found that locus 142 was the recognition site for EcoR72I (Fig. 2). There were 2 bands in epilepsy patients (S1-S2) TSC1 after digested by EcoR72I; there were 3 bands in healthy population (S3-S4) TSC1 gene after digested by EcoR72I.

TSC1 mRNA expression in the control and observation groups. The total RNA was extracted from patients with epilepsy and healthy people. The difference of TSC1 mRNA expression in different subjects was determined by fluorescence quantitative PCR. The results are shown in Fig. 3. It can be seen from the figure that there was no significant difference in TSC1 mRNA expression between epilepsy patients and healthy people $(\mathrm{P}>0.05)$. 


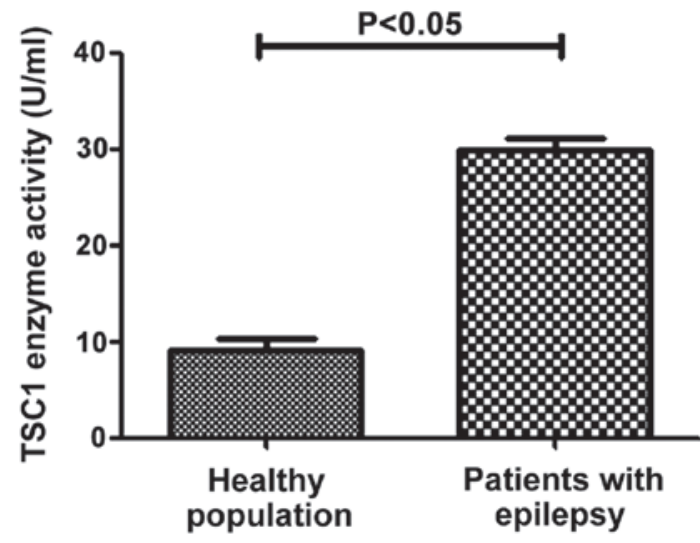

Figure 5. Detection of tuberous sclerosis complex 1 (TSC1) protein activity in the control and observation groups by enzyme-linked immunosorbent assay (ELISA). It can be seen from the figure, there was a significant difference in TSC1 enzyme activity between epilepsy patients and healthy people.

TSC1 protein expression in the control and observation groups. The expression of TSC1 protein in epilepsy patients and healthy people was determined by western blot method. The results are shown in Fig. 4. It can be seen from the figure that there was no significant difference in the protein expression of TSC1 protein between epilepsy and healthy people $(\mathrm{P}>0.05)$, which indicated that polymorphism of locus $142 \mathrm{did}$ not affect TSC1 gene expression.

ELISA detection of TSC1 protein activity in the control and observation groups. The activity of TSC1 protein in different samples was determined by ELISA method. The results in Fig. 5 shows that the activity of TSC1 protein in healthy population $(8.95 \pm 2.41 \mathrm{U} / \mathrm{ml})$ was significantly lower than that in patients with epilepsy $(29.27 \pm 4.06 \mathrm{U} / \mathrm{ml})$, the difference was statistically significant $(\mathrm{P}<0.05)$. This suggested that mutations of TSC1 in patients with epilepsy can lead to elevated TSC1 enzyme activity.

SWISS-MODEL homology modeling analysis. In this study, we found that TSC1 activity in patients with epilepsy was significantly higher than that in healthy people. The three-dimensional structure of TSC1 protein was predicted by SWISS-MODEL software (Swiss Institute of Bioinformatics, Basel, Switzerland), the results are shown in Fig. 6. It was found that locus 142 was located at the TSC1 protein active center, which revealed the reason of increased activity of TSC1 after locus 142 mutation in epilepsy patients.

\section{Discussion}

Clinical data show that (13), the sensitivity of epilepsy drugs against epilepsy is gradually reducing. With the deepening of epilepsy research in recent years, it was found that the main cause of antiepileptic symptoms was the mutation of antiepileptic drug target site in the human body or the change of the three-dimensional structure of the protein, making the original antiepileptic drug identification site wrapped within the three-dimensional structure of the protein (14-16), so that the antiepileptic drug cannot bind with the target site and eventually lost effect. For example, the study found that (17), GABAAR, as the current recognized antiepileptic drug recognition site, the main structure is ion channel composed of five subunits (including $\alpha 1-6, \beta 1-4$ and $\lambda 1-3$ ), studies found that in patients with epilepsy disease, the expression of $\beta 1-4$ protein decreased, and with the duration of disease gradually extending, the protein expression showed a gradual decreasing trend $(18,19)$. This suggests that changes in antiepileptic drug interaction target site and mutations can both lead to occurrence and progression of epilepsy in patients (20). In this study, we found that TSC1 gene in the epileptic patients and healthy human showed a certain polymorphism, that is, there were significant differences in the base at locus 142, locus 142 in healthy population was mainly CC (79.3\%), while in the epilepsy patients was predominantly CA (26.4\%) and AA (52.3\%), there was significant difference between the two groups $(\mathrm{P}<0.05)$. However, there was no significant difference between the two groups in terms of the TSC1 gene mRNA and protein expression between the healthy population and epilepsy patients $(\mathrm{P}>0.05)$. The ELISA results showed that the activity of $\mathrm{TSC} 1$ protein in patients with epilepsy

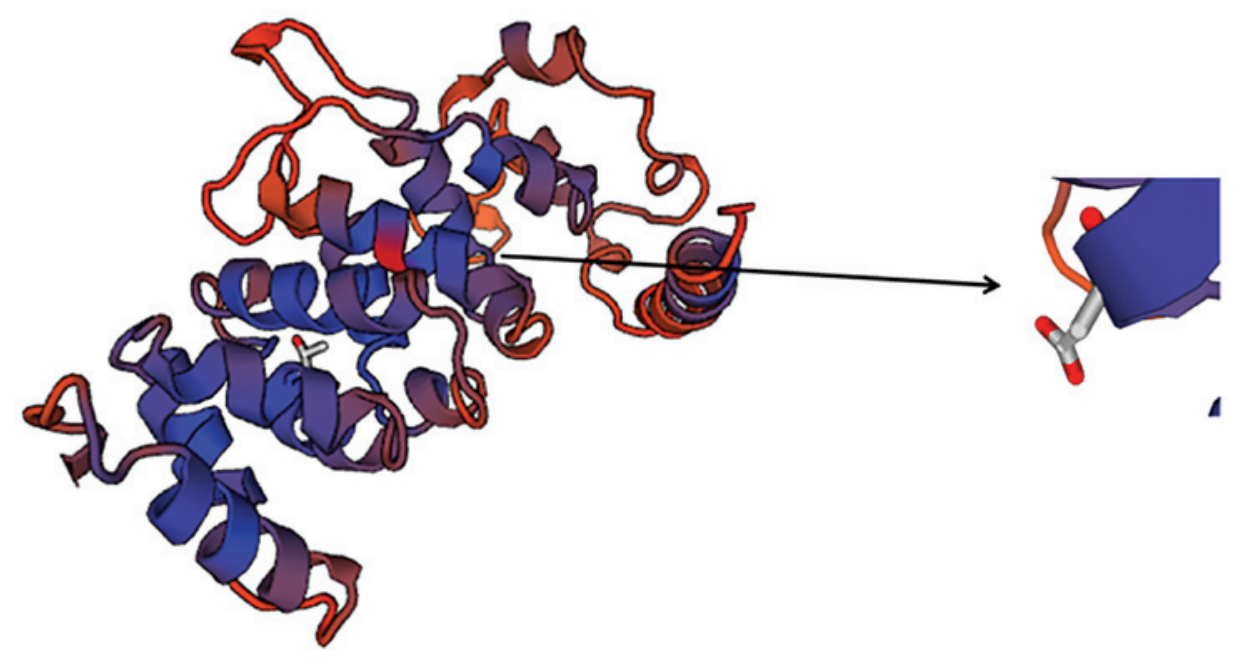

Figure 6. Analysis of tuberous sclerosis complex 1 (TSC1) protein homology modeling. The SWISS-MODEL homology modeling revealed that the locus 142 (the rod-like structure indicated by the arrow) was the active center of TSC1 protein. 
$(29.27 \pm 4.06 \mathrm{U} / \mathrm{ml})$ was significantly higher than that in healthy population $(8.95 \pm 2.41 \mathrm{U} / \mathrm{ml})$, which indicated that locus 142 polymorphisms could promote the occurrence of epilepsy, that is, the increased CC content was more likely to cause epilepsy. By SWISS-MODEL, it was found that the locus 142 was mainly located in the TSC1 protein activity center, and the change of the base in the locus could significantly affect the protein activity.

\section{References}

1. Faure JB, Marques-Carneiro JE, Akimana G, Cosquer B Ferrandon A, Herbeaux K, Koning E, Bar-belivien A, Nehlig A and Cassel JC: Attention and executive functions in a rat model of chronic epilepsy. Epilepsia 55: 644-653, 2014.

2. Fernández-Gajardo R, Matamala JM, Carrasco R, Gutiérrez R, Melo R and Rodrigo R: Novel therapeutic strategies for traumatic brain injury: Acute antioxidant reinforcement. CNS Drugs 28: 229-248, 2014

3. Rowley S and Patel M: Mitochondrial involvement and oxidative stress in temporal lobe epilepsy. Free Radic Biol Med 62: 121-131, 2013.

4. Korczyn AD, Schachter SC, Brodie MJ, Dalal SS, Engel J Jr, Guekht A, Hecimovic H, Jerbi K, Kanner AM, Johannessen Landmark C, et al: Epilepsy, cognition, and neuropsychiatry (Epilepsy, Brain, and Mind, part 2). Epilepsy Behav 28: 283-302, 2013.

5. de Figueiredo SM, Filho SA, Nogueira-Machado JA and Caligiorne RB: The anti-oxidant properties of isothiocyanates: A review. Recent Pat Endocr Metab Immune Drug Discov 7: 213-225, 2013.

6. Kan MC, Wang WP, Yao GD, Li JT, Xie T, Wang W and Ma WQ: Anticonvulsant effect of dexmedetomidine in a rat model of self-sustaining status epilepticus with prolonged amygdala stimulation. Neurosci Lett 543: 17-21, 2013.

7. Howard BA and Lu P: Stromal regulation of embryonic and postnatal mammary epithelial development and differentiation. Semin Cell Dev Biol 25-26: 43-51, 2014.

8. Liu X, Ory V, Chapman S, Yuan H, Albanese C, Kallakury B, Timofeeva OA, Nealon C, Dakic A, Simic V, et al: ROCK inhibitor and feeder cells induce the conditional reprogramming of epithelial cells. Am J Pathol 180: 599-607, 2012.

9. Düvel K, Yecies JL, Menon S, Raman P, Lipovsky AI, Souza AL, Triantafellow E, Ma Q, Gorski R, Cleaver S, et al: Activation of a metabolic gene regulatory network downstream of mTOR complex 1. Mol Cell 39: 171-183, 2010.
10. Bissler JJ, Kingswood JC, Radzikowska E, Zonnenberg BA, Frost M, Belousova E, Sauter M, Nonomura N, Brakemeier S, de Vries PJ, et al: Everolimus for angiomyolipoma associated with tuberous sclerosis complex or sporadic lymphangioleiomyomatosis (EXIST-2): A multicentre, randomised, double-blind, placebo-controlled trial. Lancet 381: 817-824, 2013.

11. Liu NK and Xu XM: Neuroprotection and its molecular mechanism following spinal cord injury. Neural Regen Res 7: 2051-2062, 2012.

12. Colín-González AL, Orozco-Ibarra M, Chánez-Cárdenas ME, Rangel-López E, Santamaría A, Pedraza-Chaverri J, BarreraOviedo D and Maldonado PD: Heme oxygenase-1 (HO-1) upregulation delays morphological and oxidative damage induced in an excitotoxic/pro-oxidant model in the rat striatum. Neuroscience 231: 91-101, 2013.

13. Morroni F, Tarozzi A, Sita G, Bolondi C, Zolezzi Moraga JM, Cantelli-Forti G and Hrelia P: Neu-roprotective effect of sulforaphane in 6-hydroxydopamine-lesioned mouse model of Parkinson's disease. Neurotoxicology 36: 63-71, 2013.

14. Zhou H, Wang N, Xu L, Huang HL and Yu CY: Clinical study on anti-epileptic drug with B vitamins for the treatment of epilepsy after stroke. Eur Rev Med Pharmacol Sci 21: 3327-3331, 2017.

15. Sanchez RM, Ribak CE and Shapiro LA: Synaptic connections of hilar basal dendrites of dentate granule cells in a neonatal hypoxia model of epilepsy. Epilepsia 53 (Suppl 1): 98-108, 2012.

16. Vittos O, Toana B, Vittos A and Moldoveanu E: Lipoproteinassociated phospholipase A2 (Lp-PLA2): A review of its role and significance as a cardiovascular biomarker. Biomarkers 17: 289-302, 2012

17. Zhao T, Li Y, Dai X, Wang J, Qi Y, Wang J and Xu K: Effects of retrograde gene transfer of brain-derived neurotrophic factor in the rostral spinal cord of a compression model in rat. Mol Biol Rep 39: 8045-8051, 2012.

18. Nakano N, Nakai Y, Seo TB, Yamada Y, Ohno T, Yamanaka A, Nagai Y,Fukushima M,Suzuki Y,NakataniT, et al: Characterization of conditioned medium of cultured bone marrow stromal cells. Neurosci Lett 483: 57-61, 2010.

19. Uriarte G, Paternain L, Milagro FI, Martínez JA and Campion J: Shifting to a control diet after a high-fat, high-sucrose diet intake induces epigenetic changes in retroperitoneal adipocytes of Wistar rats. J Physiol Biochem 69: 601-611, 2013.

20. Lovinsky-Desir S and Miller RL: Epigenetics, asthma, and allergic diseases: A review of the latest advancements. Curr Allergy Asthma Rep 12: 211-220, 2012. 